(1) Excessive pharyngeal secretions irritating the vocal chords may have initiated laryngeal spasm and respiratory arrest, the consequent hypoxia in turn provoking cardiac arrest. When pharyngeal insufflation via a facemask is used in such circumstances air is delivered under pressure to both the vocal cord and the cricopharyngeal sphincter. The reflex activity of the glottis is greater than that of the cricopharyngeus, and therefore the air will simply pass through the cricopharyngeal sphincter and dilate the stomach.

(2) Simple airway obstruction with hypoxia followed by cardiac arrest and attempts at forced ventilation would tend to distend the stomach. The chest was noted to inflate, however, and the patient's cyanosis and general condition improved, so that this explanation is unlikely.

(3) Pharyngeal suction may have induced a "vagal reflex." This, however, would not specifically predispose to gastric distension and is thus unlikely.

Whatever the cause, endotracheal intubation will clearly avert this complication of resuscitation and should be employed as soon as possible.

1 Anthony, P. P., and Petersfield, A. E., British Heart fournal, 1969, 31, 72. 2 Valloren, E. J., and Hakota, N., Acta Chirurgica Scandinavica, 1964, 127, 427.

3 Demos, N. J., and Poticha, S. M., Surgery, 1964, 55, 364.

4 Gain, E. A., Canadian Anaesthetists' Society fournal, 1958, 5, 72.

5 Fenton, E. S. M., British Fournal of Anaesthesia, 1956, 28, 220.

Whipps Cross Hospital, London E11

S. G. DARKE, F.R.C.S., Senior Surgical Registrar (Now Senior Surgical Registrar, The London Hospital, London E1 1BB)

St. James's Health Centre, London E.17

E. BLOOMFIELD, M.B., D.oBST.R.C.o.G., General Practitioner

\section{Effect of Fibrinolytic Treatment in Malignant Atrophic Papulosis}

Malignant atrophic papulosis (Köhlmeier-Degos) is a rare multisystem disease characterized by typical skin lesions and multiple gastrointestinal infarctions. The mortality from the disease is about $60 \%$ and it does not respond to either systemic steroid or immunosuppressive treatment. ${ }^{1}$ The small blood vessels are conspicuously involved in the disease process and there is impairment of tissue fibrinolysis in the skin lesions. ${ }^{2}$ The beneficial effects of phenformin and ethyloestrenol in treating other forms of cutaneous vasculitis ${ }^{3}$ prompted us to try this treatment in a patient with malignant atrophic papulosis.

\section{Case Report}

A 42-year-old woman presented in 1973 with a pruritic papular eruption of two years' duration. Examination showed about 50 typical Degos papules (up to $0.5 \mathrm{~cm}$ diameter) at various stages of development scattered on the trunk and limbs (fig.). She had no gastrointestinal symptoms and her general condition was otherwise normal. Skin biopsy showed a central mucincontaining necrobiotic area in the dermis with endothelial swelling in small blood vessels. Fibrinolysis autography ${ }^{4}$ of frozen sections of a Degos papule showed a wedge-shaped area of absent fibrinolysis in the centre, and direct immunofluorescence diffuse fibrin staining around small blood vessels. The euglobulin lysis time was two and a half hours (normal). All other haematological, biochemical, and radiological findings were normal. Throughout the early months of 1974 she continued to develop two or three new lesions weekly. In April 1974, phenformin $50 \mathrm{mg}$ twice daily and ethyloestrenol $2 \mathrm{mg}$ four times daily were begun. A month later the pruritus had stopped and no new lesions had appeared. She was last seen in May 1975, when all the remaining papules had become smaller with atrophic porcelain-white centres. The euglobulin lysis time had remained at two and a half hours.

\section{Comment}

We believe this to be the first case of malignant atrophic papulosis in which fibrinolytic treatment has been tried. The response to treatment in the past year has been gratifying in that the formation of new skin lesions has been suppressed. We are aware that this is an uncontrolled observation and that the natural history of the disease may not have been altered. We submit, however, that fibrinolytic treatment is simple and safe and is therefore worth considering in a con-

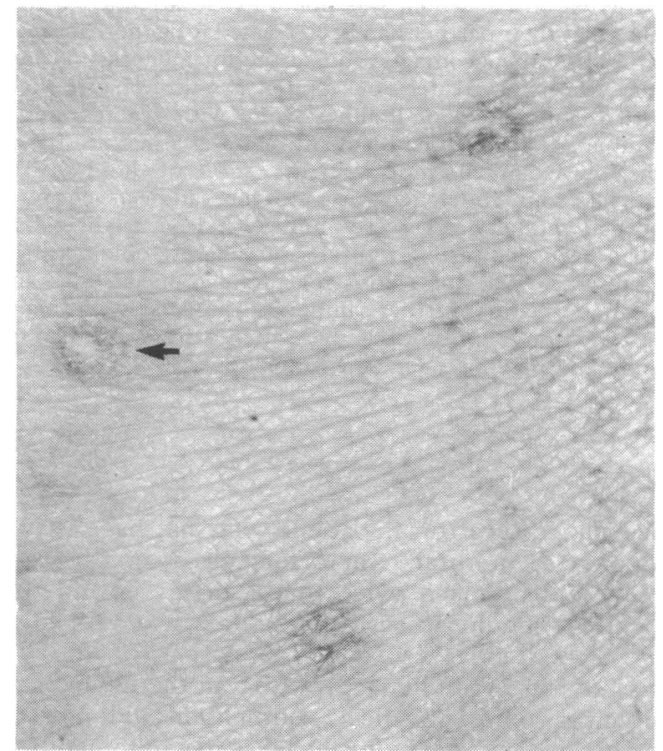

Appearances of three Degos papules on the arm at various stages of development. Late lesion (arrowed) shows typical porcelain-white centre.

dition with such a potentially high mortality for which there is at present no effective treatment.

We should like to thank Dr. S. C. Gold for encouragement in making this report, and Dr. T. J. Ryan for the fibrinolysis autographs. The case was presented at the dermatology section meeting of the Royal Society of Medicine on 16 May 1974.

${ }^{1}$ Black, M. M., British fournal of Dermatology, 1971, 85, 290.

2 Black, M. M., Nishioka, K., and Levene, G. M., British fournal of Dermatology, 1973, 88, 213.

3 Dodman, B., et al., British Medical fournal, 1973, $2,82$.

4 Turner, R. H., and Ryan, T. J., Transactions of the St. Fohn's Hospital Dermatological Society, 1969, 55, 212.

Department of Dermatology, St. George's Hospital, London

T. J. DELANEY, M.B., M.R.C.P., Senior Registrar

Department of Histopathology, Institute of Dermatology, London

M. M. BLACK, M.D., M.R.C.P., Consultant and Senior Lecturer

\section{Asymptomatic Urethral Gonorrhoea in Men}

The presence of asymptomatic female carriers of gonorrhoea has been recognized for many years and is an important factor in the disease's persistence. The concept of asymptomatic infection in the male was described nearly 20 years ago. ${ }^{1}$ Two recent studies at the Norfolk Venereal Disease Clinic, Virginia, showed that about $10 \%$ of men exposed to women with culture-proved gonorrhoea harboured organisms in their urethrae without showing signs or symptoms. ${ }^{2}$ These men are potentially infectious and are more likely to develop complications, ${ }^{3}$ and Hunter Handsfield et al. ${ }^{4}$ have emphasized that they form a reservoir of asymptomatic carriers. We report here on 24 such patients.

\section{Patients and Methods}

Over seven months 24 cases of asymptomatic gonococcal urethritis were seen by one doctor (P.M.P.). None of the 24 patients had symptoms such as discomfort during micturition or urethral discharge. From a public health point of view what the patient perceives as symptoms of gonorrhoea or a sexually transmitted disease is more important than the finding of signs during examination by the physician. 
Twelve patients, one of whom was homosexual, attended with a contact note indicating that their partner had been treated for gonorrhoea; three were advised to attend by their contacts; four came for a check-up (one had had a contact who was being treated for salpingitis); three had noticed genital warts; and two complained of itchiness (one with scabies, and one with pediculosis pubis). No patient had had antibiotic treatment in the preceding three months. On examination six patients (three of those with a contact note, one who had come for a check-up, one who had been sent by a contact, and one who had genital warts) were found to have a urethral discharge of which they had been unaware. Urethral samples were obtained from all the patients by sterilized platinum loops for Gram-stained slides and microscopical examination, and a further sample was inoculated on to a Columbia blood agar plate without antibiotics. Five patients did not return for followup examination and may have remained infectious.

\section{Discussion}

To minimize diagnostic errors in patients who may have asymptomatic urethral gonorrhoea urethral scrapes for microscopical examination and culture should be taken twice, at the first visit and a fortnight later. The patient should be advised to retain urine for at least two hours before each attendance.

A recent study ${ }^{5}$ of 505 military personnel in the United States who were undergoing routine medical examination did not show any evidence of gonorrhoea on culture. Most asymptomatic disease is found in high-risk groups-that is, male sexual contacts of known patients and male attenders at venereal disease clinics. A larger survey is proposed to estimate more accurately the extent of the problem in the United Kingdom and to indicate methods by which this hidden reservoir of infection can be reduced. Meanwhile general practitioners and other doctors should not assume that symptomless men are necessarily free from sexually transmitted disease, and male contacts of women with gonorrhoea should be examined even if they insist they have no symptoms.

We thank Drs. R. D. Catterall and J. R. Seale for their advice in preparing this manuscript.

1 Bittner, J. B., and Horne, G. O., British fournal of Venereal Diseases, 1955, 31, 155.

2 Pariser, H., Medical Clinics of North America, 1972, 5, 1127.

3 Holmes, K. K., Annals of Internal Medicine, 1971, 75, 470.

4 Hunter Handsfield, H., et al., New England fournal of Medicine, 1974, 290, 117.

5 Thatcher, R. W., et al., fournal of The American Medical Association, $1969,210,315$.

\section{$\theta^{\prime}$ Adult Toxocaral Infection with Focal Retinal Lesion}

The second-stage larva of Toxocara canis may produce retinal granulomata, ${ }^{1}$ endophthalmitis, ${ }^{2}$ or optic neuritis. ${ }^{3}$ Such lesions occur mostly in children, and the habit of geophagy in infancy may be a method by which the ova, excreted in the faeces of infested dogs, enter the human alimentary tract. Fluorescent antibody tests for toxocariasis in healthy blood donors produced positive reactions in $4.5 \%$ of the $18-25$-year-olds and $7 \cdot 1 \%$ of the $30-40$-year-olds. ${ }^{4}$

\section{Case Report}

On 27 July 1974 a 50-year-old man complained of malaise, anorexia, and night sweats of sudden onset but general examination three days later showed no abnormality. On 6 August an eosinophilia of over $2 \times 10^{\circ} / 1$ and a plasma viscosity of $2.0 \mathrm{cP}$ were reported. A week later the patient noted blurred vision, distortion of images, and micropsia in his right eye associated with ocular pain radiating to the scalp and face on the same side. On admission to hospital on 16 August his systemic symptoms had resolved and general examination again showed no abnormality. Investigations excluded toxoplasmosis, autoimmune disease, $Q$ fever, liver disease, spirochaetal infection, undulant fever, psittacosis, Coxsackie $B$ virus, and tuberculosis. The eosinophil count had fallen to $0.7 \times 10^{9} / 1$ and the plasma viscosity to $1.7 \mathrm{cP}$. Since the ocular symptoms persisted an ophthalmic opinion was obtained. Visual acuities were $6 / 12$ right and $6 / 6 \mathrm{left}$, and in the right fundus a small discrete disciform lesion was noted above and temporal to the macula containing a thin linear opacity with its axis oriented vertically.

On questioning, the patient stated that he had acquired a puppy about five weeks before the onset of his illness. The response to a toxocaral fluorescent antibody test proved positive. The retinal lesion was treated with light coagulation, and from the next day the patient had no further pain. Six months later the visual acuity was $6 / 12$, the ocular symptoms and retinal oedema had resolved, and no linear opacity could be discerned.

Just before treatment retinal fluorescein studies showed a pigment epithelial detachment and the linear opacity had rotated to the horizontal (see fig.). Repeat fluorescein angiography two months later showed only the typical pigmentary clumping and atrophy resulting from light coagclation.

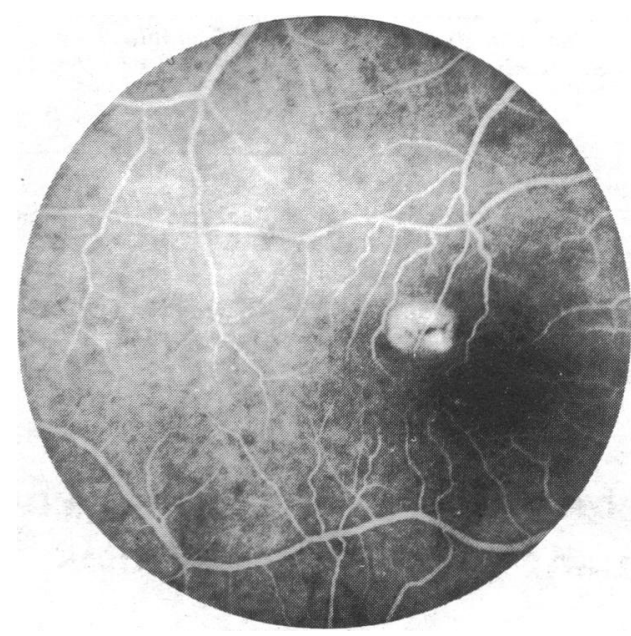

Residual-phase angiogram showing linear opacity and pooling of dye beneath pigment epithelium.

\section{Discussion}

The presence of a raised retinal lesion containing a linear opacity that changed its position associated with an eosinophilia strongly suggested a nematode infection. The recent acquisition of a puppy and the presence of toxocaral antibodies made the diagnosis of toxocariasis highly probable.

We are unaware of other reports of ocular toxocaral infection in patients of this age but there appear to be ample opportunities for ingesting ova by persons of any age handling infested dogs or contaminated soil..$^{5}$

A further six patients aged 20-44 years observed by us had similar presenting symptoms and developed exudative disciform lesions with retinal fibrosis. All gave positive reactions to fluorescent antibody tests for toxocara. Adult ocular infection may therefore be more common than was previously thought. Diethylcarbamazine treatment was not considered because of evidence that the dead larva promotes a more vigorous cellular response. Immunological isolation of the lesion and surrounding tissues was therefore attempted by applying light coagulation. This appears to have been effective in a case detected before a fibrotic reaction had occurred.

1 Ashton, N., British Medical fournal, 1960, 44, 129.

2 Duguid, I. M., British Fournal of Ophthalmology, 1961, 45, 705.

3 Bird, A., American fournal of Ophthalmology, 1970, 69, 74.

4 Woodruff, A. W., Transactions of the Royal Society of Tropical Medicine and Hygiene, 1973, 67, 755.

5 Borg, O. A., and Woodruff, A. W., British Medical fournal, 1973, 4, 470.

Bristol Eye Hospital, Bristol BS1 2LX

E. R. RAISTRICK, M.B., CH.B., Clinical Assistant in Ophthalmology J. C. DEAN HART, B.SC., F.R.C.S., Senior Lecturer in Ophthalmology 